CLINICAL STUDY

\title{
Circulating and cerebrospinal fluid ghrelin and leptin: potential role in altered body weight in Huntington's disease
}

Vera Popovic, Marina Svetel ${ }^{1}$, Marina Djurovic, Smiljka Petrovic ${ }^{2}$, Mirjana Doknic, Sandra Pekic, Dragana Miljic, Natasa Milic ${ }^{3}$, Jovana Glodic ${ }^{4}$, Carlos Dieguez ${ }^{5}$, Felipe F Casanueva ${ }^{6}$ and Vladimir Kostic ${ }^{1}$

Neuroendocrine Unit, Institute of Endocrinology, ${ }^{1}$ Institute of Neurology, ${ }^{2}$ Orthopedic Anaesthesiology, ${ }^{3}$ Medical Statistics, University Clinical Centre, Belgrade, Serbia, ${ }^{4}$ Consilium Laboratory, ${ }^{5}$ Department of Physiology and ${ }^{6}$ Department of Medicine, Complejo Hospitalario Universitario de Santiago, Santiago de Compostela University, Spain

(Correspondence should be addressed to V Popovic; Email: popver@Eunet.Yu)

\begin{abstract}
Objective: In addition to neurological impairment, weight loss is a prominent characteristic of Huntington's disease (HD). Neuropathologically, the disease affects the caudate nucleus and the cerebral cortex, and also the hypothalamus. The recently discovered orexigenic hormone of gastric origin, ghrelin and the adipocyte hormone leptin, are two peripherally produced hormones exerting opposite effects on specific populations of hypothalamic neurons that play a key role in regulating energy intake and energy output. The aim of this study was to investigate the possible involvement of cerebrospinal fluid (CSF) and circulating ghrelin and leptin in the regulation of energy balance in patients with HD.

Methods: Twenty healthy normal-weight subjects undergoing orthopedic surgery, and fifteen patients with genetically verified HD, were enrolled in this study. The unified Huntington's disease rating scale (UHDRS) was used to assess clinical course of the disease. Blood samples for hormonal measurements were obtained by venipuncture and in-parallel CSF samples for leptin/ghrelin determination were obtained by lumbar puncture.

Results: Patients with HD had increased concentrations of ghrelin in plasma compared with healthy subjects $(4523.7 \pm 563.9$ vs $2781.1 \pm 306.2 \mathrm{pg} / \mathrm{ml}, P<0.01)$. On the other hand, patients with HD had decreased concentrations of leptin in plasma compared with healthy subjects $(4.8 \pm 1.6$ vs $10.9 \pm 2.4 \mathrm{ng} / \mathrm{ml}, P<0.01)$. The concentrations of CSF ghrelin and CSF leptin were equivalent to values in healthy subjects. No correlation was found between disease duration - and other clinical features of HD - and plasma or CSF leptin/ghrelin levels. In patients with HD, baseline levels of GH, IGF-I, insulin and glucose did not differ from those in healthy subjects.

Conclusion: High circulating ghrelin and low leptin levels in patients with HD suggest a state of negative energy balance. Early nutritional support of patients with HD is advocated since patients with HD and higher body mass index at presentation have slower progression of the disease.
\end{abstract}

European Journal of Endocrinology 151 451-455

\section{Introduction}

A robust physiological system acts to maintain relative constancy of weight. The available data suggest that the concentration of afferent signals is sensed by groups of neurons in the hypothalamus and other brain regions and the neural circuits regulating weight are likely to be complex (1).

Huntington's disease (HD) is a genetic, autosomal dominant, degenerative brain disorder, which neuropathologically strikes the caudate nucleus, cerebral cortex and hypothalamus. Weight loss is a prominent characteristic of HD and the basis of wasting is unclear. Selective neuronal loss in the hypothalamic lateral tuberal nucleus in HD patients has been shown (2).
Recently, the protein product of the HD gene, huntingtin, was shown to be increased in the arcuate nucleus of postpartum female animals, yet its function is currently unknown (3). Weight loss in HD occurs in spite of an adequate caloric intake (4). Higher body mass index (BMI) at presentation is associated with slower disease progression. These features have been observed in transgenic mice (5).

Both acute and chronic alterations in energy balance or nutritional status may be relayed to the hypothalamic arcuate nucleus by neuronal pathways or via alterations in the levels of cirulating hormones. Ghrelin, the recently discovered orexigenic hormone of gastric origin, may provide an endocrine link between the stomach and the central circuits involved with the 
regulation of energy intake and growth hormone $(\mathrm{GH})$ release $(6-10)$. Plasma levels of ghrelin are lower in obese subjects compared with lean subjects (11). In contrast, states such as fasting and anorexia nervosa are characterized by increased plasma ghrelin levels (12). Leptin, the adipocyte hormone, is believed to act tonically as an afferent signal from adipose tissue to the brain, in particular the hypothalamus, as part of a negative feedback loop regulating the size of energy stores and energy balance $(13,14)$. Body fat significantly contributes to leptin levels and thus plasma leptin levels are elevated in obesity and conversely decreased in anorexia nervosa $(15,16)$.

Recently ghrelin has been measured in human cerebrospinal fluid (CSF) and a negative association between fasting CSF ghrelin levels and BMI was found (17). Leptin is transported across the blood-brain barrier (BBB) and has been measured in CSF in healthy subjects, and in patients with anorexia nervosa or obesity $(18,19)$. A significant positive correlation between leptin concentrations in the CSF and plasma in healthy normal-weight subjects was found. CSF leptin levels in anorexia nervosa correlated with nutritional status. There is indirect evidence for impaired transport of leptin across the BBB in obesity (18).

In order to investigate the possible involvement of ghrelin and leptin in the regulation of metabolic balance, in this study we measured plasma and CSF ghrelin and leptin in a group of healthy subjects at normal weight and in patients with HD.

\section{Materials and methods}

\section{Study subjects}

After providing informed consent, 20 healthy normalweight subjects and 15 patients with HD were studied. The protocol was approved by the University Hospital Ethics Committee. Fifteen HD patients (nine female and six male; age $48.9 \pm 3.2$ years) admitted at the Institute of Neurology participated in the study. They had been previously genetically diagnosed, were stable, medication free and had no other concurrent medical illness; they consumed an average hospital diet. The patient's signs and symptoms were rated using the unified Huntington's disease rating scale (UHDRS), disability scale (DS) and functional disability scale (FDS) as part of their ongoing clinical care and evaluation. Duration of illness was calculated as the difference between the date of initial evaluation and the date of onset of symptoms or signs. Blood samples were obtained by venipuncture in parallel with CSF samples $(1 \mathrm{ml})$ obtained by lumbar puncture after overnight fast at $0900 \mathrm{~h}$.

Twenty healthy subjects (nine female and 11 male; age 46.2 \pm 4.1 years) admitted to an Orthopedic Clinic for minor surgery were enrolled in this study. All were non-obese, led normal lives and were taking no drugs; they consumed a similar hospital diet. CSF samples were obtained by lumbar puncture in the fasting state at the time of spinal anesthesia before anesthetic agents were given; blood samples were obtained by venipucture in parallel. Plasma samples and CSF were collected on ice and immediately stored at $-80^{\circ} \mathrm{C}$.

The BMI was calculated as weight divided by the square of height $\left(\mathrm{kg} / \mathrm{m}^{2}\right)$.

\section{Hormone measurements}

Leptin levels were measured using RIA Linco kits (St Charles, MO, USA) with the limit of detection being $0.5 \mathrm{ng} / \mathrm{ml}$. Within-assay coefficient of variation was between 4.6 and $6 \%$. Interassay variations were $6.8-9.5 \%$. All assays were run in duplicate.

Ghrelin (total) was subsequently measured using Linco RIA with the limit detection being $100 \mathrm{pg} / \mathrm{ml}$. Within-assay coefficient of variation was between 5.6 and $8 \%$. Interassay variations were $7.8-9.8 \%$. All assays were also run in duplicate. For hormone assays CSF samples were concentrated fourfold in a vacuum lyophilizer, and ghrelin and leptin were subsequently measured.

GH levels were measured using time-resolved fluoroimmunometric assay (Wallac, Turku, Finland) with a GH sensitivity of $0.011 \mu \mathrm{g} / \mathrm{l}$, and coefficients of variation of $6.3 \%(0.4 \mu \mathrm{g} / \mathrm{l}), 5.3 \%(10.2 \mu \mathrm{g} / \mathrm{l})$ and $4.2 \%$ (43.4 $\mu \mathrm{g} / \mathrm{l})$.

Insulin levels were measured using RIA kits (INEP, Zemun, Yugoslavia) with the limit of detection being $0.60 \mathrm{mU} / \mathrm{l}$. Within-assay coefficient of variation was between 2.5 and $5.2 \%$. Interassay variations were $7.7-10.7 \%$.

Insulin-like growth factor-I (IGF-I) levels were measured using enzyme-labeled chemiluminescent immunometric assay (Immulite 2000 IGF-I, DPC, LA, USA) with the limit of detection being $20 \mathrm{ng} / \mathrm{ml}$. Within-assay coefficient of variation was between 2.3 and $3.9 \%$. Interassay variations were $3.7-8.1 \%$.

Blood glucose levels were measured using Beckman Glucose Analyzer 2 (Fullerton, CA, USA).

\section{Statistical analysis}

Group values are reported as the mean \pm S.E. Leptin values were non-Gaussian distributed and thus were logarithmically transformed before analysis. Student's paired $t$-test was used. Relationships between CSF leptin/ghrelin and plasma leptin/ghrelin and body weight were assessed by Pearson correlation. Correlations of disease duration, DS, FDS and UHDRS with plasma leptin/ghrelin and CSF leptin/ghrelin were analysed by Spearman correlation. All analyses were performed using the SPSS package. A $P$ value of less than 0.05 was considered to be statistically significant. 


\section{Results}

The clinical characteristics of 20 healthy subjects and 15 patients with HD are shown in Table 1. Plasma ghrelin concentrations in patients with HD were significantly elevated compared with those of healthy controls (Table 1, Fig. 1) (4523.7 \pm 563.9 vs $2781.1 \pm 306.2 \mathrm{pg} / \mathrm{ml}, P<0.01)$. There was no difference in CSF ghrelin levels in patients with $\mathrm{HD}$ and healthy subjects (Fig. 1).

Plasma leptin levels were significantly decreased in patients with HD in comparison with healthy subjects (Table 1, Fig. 2). CSF leptin levels were not different from healthy subjects (Fig. 2). Plasma leptin levels were significantly lower in male patients with $\mathrm{HD}$ in comparison with healthy males $(1.2 \pm 0.4$ vs $7.8 \pm 3.1 \mathrm{ng} / \mathrm{ml}, \quad P<0.05)$ and in female patients with HD in comparison with healthy females $(3.8 \pm 1.5$ vs $14.3 \pm 4.9 \mathrm{ng} / \mathrm{ml}, P<0.05)$.

Plasma ghrelin concentrations did not correlate with BMI either in controls or in patients with HD. As expected, plasma leptin did correlate with BMI, but only in healthy subjects $(r=0.572)$ and not in patients with HD $(r=0.178)$. CSF ghrelin and leptin did not correlate with plasma ghrelin and leptin levels in healthy or in $\mathrm{HD}$ patients.

Table 1 Characteristics of healthy subjects and patients with HD.

\begin{tabular}{lccc}
\hline & $\begin{array}{c}\text { Healthy } \\
(n=20)\end{array}$ & $\begin{array}{c}\text { HD } \\
(n=15)\end{array}$ & $\boldsymbol{P}$ \\
\hline Age (years) & $46.2 \pm 4.1$ & $48.9 \pm 3.2$ & n.s. \\
BMl (kg/m $\left.{ }^{2}\right)$ & $24.8 \pm 0.8$ & $20.2 \pm 0.6$ & 0.001 \\
Ghrelin plasma $(\mathrm{pg} / \mathrm{ml})$ & $2781.1 \pm 306.2$ & $4523.7 \pm 563.9$ & 0.007 \\
Ghrelin CSF $(\mathrm{pg} / \mathrm{ml})$ & $414.8 \pm 15.6$ & $453.0 \pm 40.8$ & n.s. \\
Leptin plasma $(\mathrm{ng} / \mathrm{ml})$ & $10.9 \pm 2.4$ & $4.8 \pm 1.6$ & 0.007 \\
Leptin CSF $(\mathrm{pg} / \mathrm{ml})$ & $301.4 \pm 40.2$ & $297.5 \pm 47.6$ & n.s. \\
Insulin $(\mathrm{mU} / \mathrm{l})$ & $15.8 \pm 3.1$ & $15.3 \pm 2.5$ & n.s. \\
IGF-1 $(\mathrm{ng} / \mathrm{ml})$ & $116.6 \pm 11.0$ & $85.0 \pm 11.3$ & n.s. \\
Growth hormone $(\mu \mathrm{g} / \mathrm{l})$ & $1.05 \pm 0.58$ & $1.23 \pm 0.54$ & n.s. \\
Glucose $(\mathrm{mmol} / \mathrm{l})$ & $4.2 \pm 0.4$ & $3.9 \pm 0.3$ & n.s. \\
\hline
\end{tabular}

n.s., $P>0.05$.

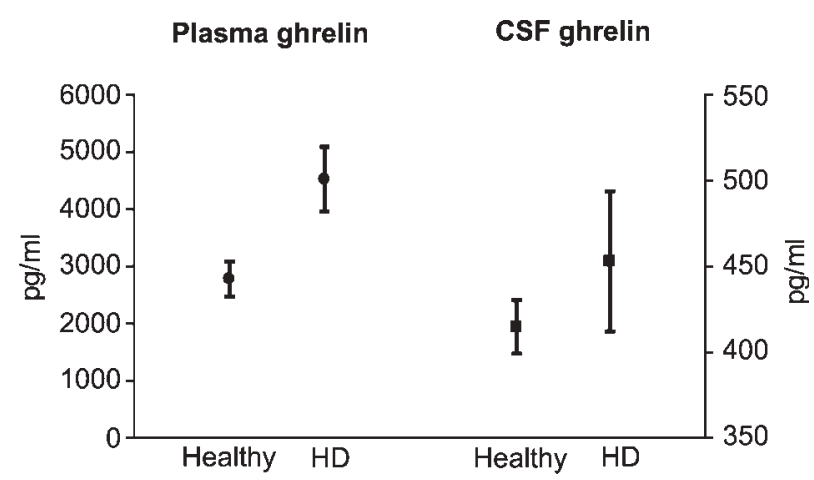

Figure 1 Plasma and CSF ghrelin levels in healthy subjects and in patients with HD (mean \pm S.E.).

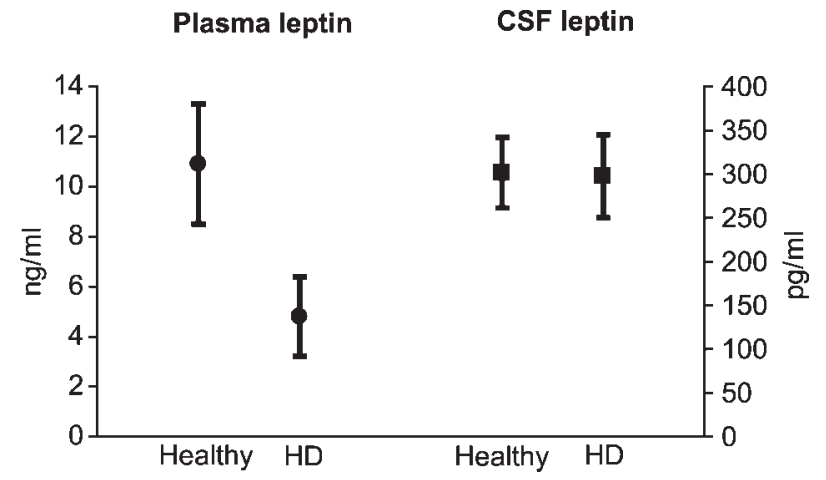

Figure 2 Plasma and CSF leptin levels in healthy subjects and patients with HD (mean \pm S.E.).

The clinical features of the HD group of patients are shown in Table 2. When HD patients were assessed to find whether CSF leptin/ghrelin and plasma leptin/ ghrelin levels correlated with the duration of the disease, disability scale (DS), functional disability scale (FDS), or unified HD rating scale (UHDRS), no significant correlation was found.

Plasma insulin, IGF-I, growth hormone and glucose levels in patients with HD were similar to those in healthy subjects (Table 1 ).

\section{Discussion}

The present study shows for first time that circulating ghrelin levels are increased and leptin levels are decreased in patients with $\mathrm{HD}$, suggesting a state of negative energy balance. The rise in circulating ghrelin and fall in plasma leptin are compensatory and serve to preserve body weight and maintain energy homeostasis. In conditions of negative energy balance in addition to suppression of leptin levels, the increase in ghrelin serves to counter further decreases in energy stores. It seems that in patients with $\mathrm{HD}$, the hypothalamic circuits through which ghrelin acts are not sensitive to perturbartions in energy balance or that the effects of ghrelin are overcome by other central system signals involved in the regulation of energy homeostasis (13). Thus elevated ghrelin concentrations in our study may reflect ghrelin resistance. The neuronal targets for both ghrelin and leptin in the hypothalamus are in the arcuate nucleus, and ventromedial and lateral hypothalamus, and these structures express high

Table 2 Clinical features of HD patients.

\begin{tabular}{|c|c|}
\hline & $\begin{array}{l}\text { HD patients } \\
\quad(n=15)\end{array}$ \\
\hline Duration of the disease (years) & $6.0 \pm 0.95$ \\
\hline Disability scale (DS) & $78.7 \pm 3.8$ \\
\hline Functional disability scale (FDS) & $9.1 \pm 0.9$ \\
\hline Unified Huntington's disease rating scale (UHDRS) & $43.8 \pm 5.5$ \\
\hline
\end{tabular}


levels of leptin and ghrelin receptors $(20,21)$. Quite clearly ghrelin and leptin appear to impose opposite effects on arcuate neuropeptide Y (NPY) neurons. Ghrelin triggers the expression of mRNA for Agouti related peptide (AGRP) and NPY while leptin induces reduction of NPY mRNA expression $(22,23)$. The involvement of orexigenic and anorexigenic pathways in weight loss in HD has not been studied so far. What has been suggested is that the selective neuronal loss in the hypothalamic lateral tuberal nucleus may play a role in the weight loss observed in the early stages of $\mathrm{HD}(2,24)$. High levels of glutamate receptors normally present in the lateral tuberal nucleus might render these neurons selectively susceptible to excitotoxic cell death. Thus severe cell loss in the lateral tuberal nucleus may underlie the catabolic state that frequently occurs in HD patients (25). Furthermore, astrocytes in the arcuate nucleus of postpartum lactating female rats have increased levels of the huntingtin protein, which might play a role in the processes that regulate neuroendocrine function (3).

Experimental studies assessing the permeability of the $\mathrm{BBB}$ to ghrelin indicate that saturable systems transport ghrelin from brain to blood and vice versa (26). A negative association between fasting CSF ghrelin levels and BMI in humans has been reported, with lowered CSF levels found in obese patients (17). In keeping with this we provide the first information on CSF ghrelin in patients with HD. CSF ghrelin levels tended to be higher among HD patients but did not reach statistical significance possibly due to the normal BMI of the patients and the relatively small sample size. The same is true for CSF leptin levels, which tended to be lower. One may speculate that with further significant weight loss CSF concentrations may change; this has been shown for CSF leptin levels in patients with anorexia nervosa (19). Our data show similar ghrelin levels in the CSF in healthy subjects and in patients with $\mathrm{HD}$, despite higher circulating levels; this rules out the possibility of ghrelin resistance due to altered transport across the BBB. On the other hand, in order to explain why CSF and serum levels of ghrelin and leptin are dissociated in our study, one also has to consider the possibility of altered transport properties of the $\mathrm{BBB}$ in $\mathrm{HD}$, as the leptin transport system seems to be regulated (27).

The transgenic model of HD, the R $6 / 2$ mouse, shows severe wasting beginning at 12 weeks of age and dies between 12 and 15 weeks. Enhanced accumulation of body fat accompanied by increased serum leptin in transgenic mice between 8 and 9 weeks was observed and this initial obesity may stem from a defect in fat breakdown by adipocytes (5). Even if adipocyte defects occur in $\mathrm{HD}$ victims and contribute to their defective weight regulation, the possibility remains that HD mutation affects other regulatory systems, including those in the hypothalamus involved in feeding and weight regulation.
We did not find any correlation between disease duration - and patient's signs and symptoms rated using standard scales - and parameters of negative energy homeostasis (leptin/ghrelin). These findings are consistent with those presented by Djousse et al. (24) who showed that even in the earliest stages of HD, patients weigh significantly less than healthy age-matched controls. The observed alterations in ghrelin and leptin levels in $\mathrm{HD}$ patients may reflect the nutritional status. Other metabolic adaptations (insulin, IGF-I, $\mathrm{GH}$ and glucose levels) to chronic energy deficits have not occurred.

In conclusion we have shown that patients with HD exhibit the hyperghrelinemia and hypoleptinemia that are markers of negative energy balance. Since patients with HD and higher BMI at presentation have slower progression of the disease, the possibility of early nutritional support should be considered.

\section{Acknowledgements}

Supported by Fondo de Investigación Sanitaria, Spanish Ministry of Health, Consellería de Educación Xunta de Galicia, the Ministerio Español de Ciencia y Tecnología and Minsitry of Science and Technology, Serbia.

\section{References}

1 Kalra S, Dube M, Pu S, Xu B, Horvath T \& Kalra P. Interacting appetite-regulating pathways in the hypothalamic regulation of body weight. Endocrine Reviews 199920 68-100.

2 Kremer B. Clinical neurology of Huntington's disease. In Huntington's Disease, 3rd edn, pp 28-61. Eds G Bates, P Harper \& L Jones. Oxford: Oxford University Press, 2002.

3 Hebb M, Denovan-Wright E \& Robertson H. Expression of the Huntington's disease gene is regulated in astrocytes in the arcuate nucleus of the hypothalamus postpartum. FASEB Journal $1999131099-1106$.

4 Turner C \& Schapira AH. Energy metabolism in Huntington's disease. In Huntington's Disease, 3rd edn, pp 309-323. Eds G Bates, P Harper \& L Jones. Oxford: Oxford University Press, 2002.

5 Fain J, del Mar N, Meade C, Reiner A \& Goldowitz D. Abnormalities in the functioning of adipocytes from R6/2 mice that are transgenic for Huntington's disease mutation. Human Molecular Genetics $200110145-152$.

6 Kojima M, Hosoda H, Date Y, Nakazato M, Matsuo H \& Kangawa K. Ghrelin is a growth-hormone-releasing acylated peptide from stomach. Nature $1999 \mathbf{4 0 2} 656-660$.

7 Tschop M, Smiley D \& Heiman M. Ghrelin induces adiposity in rodents. Nature $2000 \mathbf{4 0 7} 908-913$.

8 Wren A, Seal L, Cohen M, Brynes A, Frost A, Murphy K, Dhillo WS, Ghatei MA \& Bloom SR. Ghrelin enhances appetite and increases food intake in humans. Journal of Clinical Endocrinology and Metabolism $2001865992-5995$.

9 Arvat E, Maccario M, Di Vito L, Broglio F, Benso A, Gottero C, Papotti M, Muccioli G, Dieguez C, Casanueva FF, Deghenghi R, Camanni F \& Ghigo E. Endocrine activities of ghrelin, a natural growth hormone secretagogue (GHS) in humans: comparison and interactions with hexarelin, nonnatural peptidyl GHS and GH-releasing hormone. Journal of Clinical Endocrinology and Metabolism 200186 1169-1174.

10 Broglio F, Benso A, Castiglioni C, Gottero C, Prodam F, Destefanis S, Gauna C, van der Lely AJ, Deghenghi R, Bo M, Arvat E \& Ghigo E. 
The endocrine response to ghrelin as a function of gender in humans in young and elderly. Journal of Clinical Endocrinology and Metabolism 200388 1537-1542.

11 Ravussin E, Tschop M, Morales S, Bouchard C \& Heiman M. Plasma ghrelin concentration and energy balance: overfeeding and negative energy balance studies in twins. Journal of Clinical Endocrinology and Metabolism 200186 4547-4551.

12 Otto K, Cuntz U, Freuhauf E, Wawarta R, Folwaczny C, Riepl RL, Heiman ML, Lehnert P, Fichter M \& Tschop M. Weight gain decreases elevated plasma ghrelin concentrations of patients with anorexia nervosa. Eururopean Journal of Endocrinology $2001145669-673$

13 Friedman M. Leptin and the neural circuit regulating body weight and metabolism. In Brain Somatic Cross-talk and the Central Control of Metabolism, pp 15-35. Eds C Kordon, I Robinson, J Hanoune, R Dantzer \& Y Christen. Berlin, Heidelberg. New York: SpringerVerlag, 2003.

14 Chin-Chance C, Polonsky K \& Schoeller D. Twenty-four-hour leptin levels respond to cumulative short-term energy imbalance and predict subsequent intake. Journal of Clinical Endocrinology and Metabolism 200185 2685-2691.

15 Considine R, Sinha M, Heiman M, Kriauciunas A, Stephens T, Nyce MR, Ohannesian JP, Marco CC, McKee LJ \& Bauer TL. Serum immunoreactive leptin concentrations in normal-weight and obese humans. New England Journal of Medicine 1996334 292-295.

16 Grinspoon S, Gulick T, Askari H, Landt M, Lee K, Anderson E, Ma Z, Vignati L, Bowsher R, Herzog D \& Klibanski A. Serum leptin levels in women with anorexia nervosa. Journal of Clinical Endocrinology and Metabolism 199681 3861-3863.

17 Tritos N, Kokkinos A, Lampadariou E, Alexiou E, Katsilambros N \& Maratos-Flier E. Cerebrospinal fluid ghrelin is negatively associated with body mass index. Journal of Clinical Endocrinology and Metabolism 200388 2943-2946.

18 Caro J, Kolaczynski J, Nyce M, Okannesian J, Opentanova I, Goldman WH, Lynn RB, Zhang PL, Sinha MK \& Considine RV. Decreased cerebrospinal-fluid serum/leptin ratio in obesity: a possible mechanism for leptin resistance. Lancet $1996 \mathbf{3 4 8}$ 159-161.

19 Mantzoros C, Flier J, Lesem M, Brewerton T \& Jimerson D. Cerebrospinal fluid leptin in anorexia nervosa: correlation with nutritional status and potential role in resistance to weight gain. Journal of Clinical Endocrinology and Metabolism $1997 \mathbf{8 2}$ $1845-1851$.

20 Kamegai J, Tamura H, Shimizu T, Ishii S, Suighara H \& Wakabayashi I. Central effect of ghrelin, an endogenous growth hormone secretagogue, on hypothalamic peptide gene expression. Endocrinology $2000 \mathbf{1 4 1} 4797-4800$.

21 Horvath T, Diano S, Sotonyi P, Heiman M \& Tschop M. Minireview: ghrelin and the regulation of energy balance - a hypothalamic perspective. Endocrinology 2001 142 4163-4169.

22 Shintani M, Ogawa Y, Ebihara K, Aizawa-Abe M, Miyanaga F, Takaya K, Hayashi T, Inoue G, Hosoda K, Kojima M, Kangawa K \& Nakao K. Ghrelin, an endogenous growth hormone secretagogue, is a novel orexigenic peptide that antagonizes leptin action through the activation of hypothalamic neuropeptide Y/Y1 receptor pathway. Diabetes $200150227-232$.

23 Cowley M, Smith R, Diano S, Tschop M, Pronchuk N, Grove KL, Strasburger CJ, Bidlingmaier M, Esterman M, Heiman ML, Garcia-Segura LM, Nillni EA, Mendez P, Low MJ, Sotonyi P, Friedman JM, Liu H, Pinto S, Colmers WF, Cone RD \& Horvath TL. The distribution and mechanism of action of ghrelin in the CNS demonstrates a novel hypothalamic circuit regulating energy homeostasis. Neuron 200337 649-666.

24 Djousse L, Knowlton D, Cupples L, Marder K, Shoulson I \& Myers R. for the Investigators of the Huntington Study Group. Weight loss in early stage of Huntington's disease. Neurology $2002591325-1330$.

25 Gutekunst C, Norflus F \& Hersch S. The neuropathology of Huntington's disease. In Huntington's Disease, 3rd edn, pp 251-275. Eds G Bates, P Harper \& L Jones. Oxford: Oxford University Press, 2002.

26 Banks W. Enhanced leptin transport across the blood-brain barrier by $\alpha 1$-adrenergic agents. Brain Research 2001899 209-217.

27 Banks W, Tschop M, Robinson S \& Heiman M. Extent and direction of ghrelin transport across the blood-brain barrier is determined by its unique primary structure. Journal of Pharmacological Experimental Therapy 2002302 822-827.

Received 20 May 2004

Accepted 6 July 2004 